\title{
E m busca de uma nova \\ pátria: o romance de \\ Portugal e de Angola \\ após a descolonização
}

\author{
I sabel Pires de Lima
}


A história recente de Portugal, confinando-nos com a nossa dimensão metropolitana de pequeneo rectângulo de praia debruçado a Ocidente, abruptamente constrangido a virar a folha da sua secular história imperial de nação navegante aberta ao Atlântico, motivou um reinteresse pela história como memória colectiva, a par de uma obsessiva e quase infantil necessidade de reclamar uma identidade nacional necessidade esta que levou mesmo Eduardo Lourenço, um dos mais interessantes ensaístas portugueses da autognose nacional, a defender a ideia de que Portugal não sofre de problemas de identidade mas de hiperidentidade (1990, p. 10).

A experiência de perda - perda historicamente prevista de um império que a estratégia ideológica do regime deposto com a "revolução dos cravos", em 25 de Abril de 1974, fizera durante cerca de 40 anos crer eterno - foi acentuadamente traumática, o que é tanto mais natural quanto passou pela dolorosa experência suplementar cerca de quinze anos de guerra colonial (entre 1961 e 1974). Claro que a euforia inicial decorrente da coincidência entre o fim da guerra colonial, a independência das ex-colónias e a nossa própria reconquista da liberdade, escamoteou o trauma, de tal modo que o mesmo E duardo Lourenço, em 1978, surpreendia-se com o facto único da derrocada do nosso império de quinhentos anos, que parecia essencial à imagem corporal, ética e metafísica de portugueses, ter acabado sem drama (1988, p.43). É claro que o tempo entretanto encarregou-se de avivar o drama.

Quando esse drama não fora ainda claramente assumido pela consciência colectiva, um novo dado surge como elemento de perturbação para a redefinição 
em curso da nossa própria imagem como país. De repente, a transpirenaica E uropa, para a qual a nossa posição geográfica e a política do orgulhosamente sós (este era um dos lei tmoti ves do regime vencido) nos haviam colocado de costas voltadas, surge como uma irmã, com a qual fizemos as pazes, uma irmã que entretanto enriquecera, enquanto nós quixotescamente continuávamos a lutar por um destino imperial; uma Europa pronta agora a ajudar-nos fraternalmente contra o pagamento de algumas facturas, claro, e a assunção da nossa vocação ou dimensão de europeus, que culturalmente nunca deixáramos de ser.

De país multirracial e multicontinental, de povo em diáspora, eis-nos tornados, ou retornados, Europa; de centro de um império, foco irradiador de civilização, mesmo que a civilização quase já só tivesse a face de uma administração repressiva e de uma guerra sem perspectiva de fim, eis-nos periferia, parentes pobres e distantes de uma E uropa rica, com tendência a irradicar tudo o que não seja ela própria, cujos centros de decisão sentimos escaparem-nos e que de nós pouco sabe. Somos um país na cauda das estatísticas? O u só uma longa praia vagamente despoluída? Somos o país de Fernando Pessoa, esse excêntrico poeta que se desmutiplica em vários? Ou um povo de velhos argonautas que pradoxalmente continua a esperar que um jovem rei, há séculos desaparecido no norte de África em mais uma aventura imperial - D.Sebastião -, atravesse séculos de bruma para cumprir a promessa de um outro poeta visionário - Camões - que para ele anunciara o destino messiânico de ser a Maravilha fatal da nossa idade.

Ora, a conjugação do clima finissecular com o circunstancialismo do nosso percurso nacional concorre, ao nível do imaginário nacional, em geral, e do imaginário cultural e literário, em particular, para um questionamento da pátria, do seu destino presente, em função de um passado entre mitificado e real, prova-o a multiplicação, dos anos 80 para cá, de oficiosos rituais rememorativos das glórias de antanho, de ensaios sobre a identidade nacional, de novas histórias de Portugal, de textos ficcionais que constituem narrativas de destino pátrio.

E Angola, a maior das colónias portuguesas em África, como vive ela a libertação do jugo colonial e a independência dura-mente conquistada? O desgaste provocado no poder instalado em Lisboa pela guerra colonial contribuiu largamente, como é sabido, para o seu derrube e a revolução do 25 de Abril de 74 consignou o fim do império e a independência de Angola, reconhecida logo no ano seguinte.

Angola é uma sociedade culturalmente dualista, fruto da especificidade do colonialismo português naquele território, responsável pela criação de uma sociedade bio-culturalmente mista desde os tempos mais recuados da colonização. Assim, a sociedade angolana actual é feita da coexistência entre uma sociedade crioula, que gravita num mundo citadino e moderno e as sociedades tradicionais ${ }^{1}$. 
A UNITA, o movimento da oposição que desde a independência liderou a luta contra o governo internacionalmente reconhecido do MPLA, a qual redundou numa sangrenta guerra civil, acusa exactamente a elite governativa e intelectual sediada em Luanda de impor os valores crioulos ao todo nacional, enquanto que ela própria, perseguindo também um caminho de modernização social, tem pelo contrário, na sua origem, uma evidente base étnica. Poder-se-á então admitir que a futura identidade cultural angolana resultará da dinâmica entre estas três razões identitárias.

Entretanto, intelectuais e políticos próximos do MPLA, com a legitimidade que lhes advém do seu passado de luta anti-colonial e do efectivo exercício do poder, veiculam, através do conceito de angolanidade, uma visão do mundo que converge numa sociedade crioula moderna, regida por uma harmonia interclassista e por uma mistura racial e étnica, adoptando como língua de unificação nacional o português e estendendo-se a todo o espaço angolano a "nacionalizar", isto é, a tornar nação. É evidente que este conceito tende a aproximar-se do devir político angolano e é um conceito operativo no sentido da construção e consolidação da nação.

Esta maneira crioula de assumir em projecto ou em utopia a angolanidade vai ter formas de expressão exemplares na actual literatura angolana.

Voltemos a Portugal. No campo do ensaio que reflecte sobre a identidade nacional, duas vias distintas têm sido percorridas, concretizando-se em discursos substancialmente diferentes: na primeira dessas vias cabem um discurso de feição mítica e ontologizante e um discurso mais mítico-psicanalítico; na segunda, que persegue uma dimensão científica, pontificam um discurso sociológico-antropológico e um discurso histórico.

O primeiro tipo, que classificámos de mítico e ontologizante, é um discurso muito voluntarista, de carácter tendencialmente nacionalista com uma longa tradição entre as nossas elites culturais. Reclama a existência de uma inequívoca identidade portuguesa e de um carácter português provenientes de um presumível génio local mitificado e mistificado. Trata-se de um discurso excessivo, profético,

1. "Deriva tal particularidadedo facto de existir em Angola desde os tempos mais recuados da colonização, pelo menos desde o século XVII, uma sociedade "culturalmente" crioula, confinada à região de língua kimbundun, que o mesmo será dizer a Luanda e seu interior, sociedade esta que tem servido às suas elites políticas e culturais de trampolim e de laboratório experimental para a integração das sociedades tradicionais num todo mais harmónico. Este facto levoume também a classificar a atitude de tais responsáveis de "criuolista", já que o seu discurso nacionalista surgia , e surge ainda, impregnado de valores crioulos que absorveram na infância, tais como o uso do português com interferências do kimbundu, a convivência inter-rácica, a tolerância dos costumes, etc." (J osé Carlos Venâncio, Literatura versus Sociedade - Uma visão antropológica do destino angolano, (1992, p. 97). 
que mais do que debruçar-se sobre o presente, toma como referência o passado ou o futuro mistificados, acreditando num destino histórico especificamente português. Assume muitos matizes e formas de expressão diversas, mais ou menos conservadores. Um dos corifeus desta tendência, António Quadros, reclama a existência de um arquétipo do homem português, capaz de dar corpo a um projecto nacional transtemporal e a uma paideia cristã-europeia portuguesa².

$\mathrm{N}$ a segunda das duas vias que definimos, dominada por uma óbvia preocupação de cientificidade, constata-se um esforço no sentido de responder não tanto às questões: qual é a nossa real identidade? há ou não uma identidade portuguesa? - revisitanto mitos e lugares comuns, mas de proceder à nossa identificação, através de estudos na área das ciências humanas. U rge conhecermo-nos realmente, nos termos de uma historiografia e naturalmente de uma sociologia ou de uma antropologia modernas, coisa que nem sempre foi possível durante a ditadura, quando as ciências humanas eram olhadas e perseguidas como couto de marxistas e quejandos.

Um dos nossos mais produtivos sociólogos actuais, B oaventura Sousa Santos, alerta ${ }^{3}$ exactamente para a necessidade de transformar o senso comum sobre os portugueses nascido das mistificações generalizantes das nossas elites culturais sobre o passado nacional, num "senso comum auto-crítico" construído a partir de um conhecimento científico-social sobre a condição de Portugal no sistema mundial, que, especificamente no contexto europeu, ele entende ser a de uma "sociedade de desenvolvimento intermédio ou semi-periférico", que cumpriu uma função de intermediação assente no império colonial e cujo modelo de desenvolvimento dos últimos anos "tem maior potencial periferizante do que centralizante". Essa novo senso comum, que permitará vislumbrar os papéis que poderão caber a Portugal num futuro mais ou menos imediato, pressupõe uma severa crítica ao pensamento mítico e psicanalítico social, defendendo a ideia de que Portugal tem um destino messiânico, que apenas na época dos descobrimentos cumpriu, e para a prossecução do qual precisa de se reencontrar consigo mesmo a sós ou nos contextos da I béria, da E uropa ou do Atlântico. À matriz comum aos discursos a que este tipo de pensamento dá origem, chama o autor jeremíada nacional: “É um discurso de decadência e de descrença e quando projecta uma ideia positiva do país fá-lo de modo elitista e desfocado e por isso está sempre à beira da frustra-

2. A bibliografia de António Quadros sobre o assunto é vasta; tem para a minha óptica de abordagem particular relevância o título A I deia de Portugal na literatura portuguesa dos últimos cem anos, (1989).

3. Boaventura de Sousa Santos, "11/1992 (Onze Teses por ocasião de mais uma Descoberta de Portugal)", Via Latina, Coimbra, maio de 1991, p. 58-64. Este artigo veio a constituir o cap.3 do livro do mesmo autor intitulado, Pela Mão de Alice - O social e o político na pós-modernidade, (1994), p.49-67. Ver ainda do mesmo autor, O Estado e a Sociedade em Portugal (1974-1988), e (org.) Portugal - Um retrato singular, (1993). 
ção, da queda e do ressentimento." (Sousa Santos, 1991, p. 63), manifestando em seu entender duas patologias principais: o iberismo e o nacionalismo.

$* * *$

Em Angola não podemos propriamente falar da emergência de uma onda ensaística do mesmo tipo, como é natural num país tão jovem e sujeito a um processo colonial tão longo como aquele que Angola sofreu. De resto, não havendo tradição ensaística enraizada, a literatura tornara-se, desde os finais do século XIX, veículo de expressão da angolanidade em gestação, isto é, da consciência de que o destino de Angola passava pela construção de uma sociedade supra-racial e de assunção da denúncia da sociedade colonial. Quer os intelectuais dessa época, quer os nativistas dos anos 20 e 30, quer depois a "geração de 50", donde virão a sair os "nacionalistas" fundadores do M PLA, todos eles recorreram à mediação da literatura nesse processo de consciencialização, independentemente da influência que sobre estes últimos viriam a exercer movimentos como a negritude ou o modernismo brasileiro. Parece, portanto, possível dizer com J osé Carlos Venâncio, ensaísta português que se tem debruçado sobre as relações entre literatura-poder-sociedade na África lusófona, que "a literatura tem ocupado em Angola o papel que em princípio estaria destinado à sociologia, antropologia ou à filosofia, domínios que ainda se encontram aí num estádio de desenvolvimento incipiente." (1992, p. 90) ${ }^{4}$

A literatura angolana vai portanto dar corpo a uma tendência que alguns críticos literários africanistas chamam de reali smo africano, isto é, uma literatura muito presa à referência histórica, recorrendo assiduamente à sátira social, mas atravessada simultâneamnete por um certo messianismo político. Aliás, enquanto o sentido social e nacional da representação estética se perdeu nas sociedades ditas "centrais", nas sociedades "periféricas", a sátira e a alegoria políticas são o modo de representação privilegiado. Como é natural, as primeiras manifestações literárias posteriores à independência tiveram como tema principal uma problemática típica de uma sociedade dualista, a relação do passado colonial e da sociedade em vias de construção, em função da experiência individual de realização parcial da utopia. Hoje, porém, outras tendências se esboçam.

Uma vez mais, voltemos a Portugal.Que se passa, aqui, no campo da ficção?

Antes de mais incluiria na ficção a primeira linhagem ensaística a que aludi. No fundo o seu típico discurso nacionalista, defendendo identidades ônticas e transtemporais e destinos de razão teleológica e transcendente, quer se assuma como mais conservador ou mais progressista, como mais iberista ou mais

4. J osé Carlos Venâncio, op. cit., p. 90. A este respeito, ver ainda deste autor, Literatura e Poder na África Lusófona, Lisboa, ICALP, 1992. 
europeísta, como mais atlantista ou mais localista, é sempre um discurso ficcional, que inventa Portugal, sobre o passado ou sobre o futuro.

Ora este ensaísmo mítico e o vastíssimo corpus ficcional, posterior a 74, centrado na autognose nacional ${ }^{5}$, são em grande parte narrativas do "ser" da pátria, narrativas de destino, em função de um passado e de um futuro míticos, narrativas de decadência e de renascença, que, portanto, convivem problematicamente com o "estar" da pátria.

Desse amplo campo ficcional possível, escolhemos dois romances da década de 80 nos quais se imagina Portugal de um modo diverso mas próximo, embora recorrendo a soluções narrativas as mais díspares:

O romance de AImeida Faria, Lusi tânia, de 1980, cuja acção decorre durante um ano entre dois domingos de Páscoa, o de 1974 e o de 1975, acontecendo entretanto o 25 de Abril, reflecte o imediatismo das reacções de várias consciências trata-se de um romance por cartas onde portanto várias subjectividades se assumem - perante o precipitar de acontecimentos nesse ano que valeu anos, não deixando se ser simultaneamente um romance de rememoriação nacional.

O romance de J osé Saramago, A J angada de Pedra, vindo a lume em 1986, é uma delirante e fantástica história, em que a Península Ibérica, Portugal e eE spanha reclamando uma vocação idêntica se desprende da Europa, exactamente pelos Pirinéus e ruma, qual uma jangada de pedra, pelo Atlântico, em busca de um destino que é também uma memória.

Os dois romances, logo ao nível dos títulos, remetem para um imaginário nacional, que de um modo mais ou menos explícito tem a ver com o mar, o velho destino da pátria. Lusi tânia, se por um lado traz ao presente as raízes rácicas mais remotas dos portugueses - lusitano povo -, por outro conduz inelutavelmente ao título do poema da gesta lusitana dos descobrimentos - Os Lusíadas -, com o qual há, de resto, um constante diálogo intertextual. A J angada de Pedra, por sua vez, é, obviamente, uma metomímia da própria pátria navegante, atlântica e aventureira.

Trata-se de narrativas de destino, em que a pátria conturbada por mudanças profundas e perturbadoras se questiona perante o presente, em função de uma memória colectiva no sentido da construção de um futuro, da apreensão em face dele ou até da impossibilidade de vislumbrá-lo. Por isso, em todos eles a memória colectiva é evocada, através de referências mítico-culturais ou apenas sugerida através de metáforas e símbolos como o mar, ou a nau, ou a viagem.

5. Pode-se referir, ao sabor da memória e sem nenhuma preocupação de um qualquer ordenamento, livro como As Fúrias de Agustina Bessa-Luís, Lusitânia, de Almeida Faria, As Naus, de Lobo Antunes, Portuguex, de Armando Silva Carvalho, O Naufrágio de Sepúlveda, de Vasco Graça Moura, A Nau de Quixibá, de A. Pinheiro Torres, A J angada de Pedra, de J osé Saramago, O Bosque Harmonioso, de Augusto A belaira, O Viúvo, de Fernando Dacosta, O Cais das Merendas, de Lídia J orge, Bestiário Lusitano, de Alberto Pimenta, Partes de África, de Helder Macedo. E a enumeração poderia continuar... 
Em Lusitânia, o decurso dos acontecimentos revolucionários vai criando na consciência dos autores das várias cartas uma sensação de derrocada da nação. Na primeira parte, perpassa ainda alguma vaga de esperança e até de comunhão na euforia infantil que generalizadamente se sente -

“naquele engano de alma ledo e cego que o O.G.E. não deixa durar muito." (p. 88),

embora visões ameaçadoras atravessem os sonos intranquilos das personagens. É o caso do fantasma do velho criado, Moisés, feito um Velho do R estelo:

"Moisés, de fraca fala, com um saber só de experiência feito, tais palavras tirou do estreito peito, que me deu vontade de fugir para não ouvir o que dizia." (p. 39)

Mas nas restantes duas partes a pátria é uma nau à deriva, esburacada no casco, que paulatinamente se vai afundando, Lisboa um mar de

“dejectos do transatlântico há quatro séculos encalhado que é esta decadente capital com aspecto de pedir que a esqueçam, que não liguem à sua retorcida insistência em existir" (p. 78).

Os Lusíadas, de Luís de Camões, enquanto epopeia nacional, símbolo da memória colectiva, são parafraseados por uma das personagens, nas vésperas do 25 de A bril, para desmistificar a pátria ${ }^{6}$, quatro meses volvidos sobre aquela data, é de novo à paráfrase d'Os Lusía das que outra personagem recorre para verbalizar o seu e o geral desnorte:

"Tantos perigos passados, tantos duros trabalhos, no mar tanta tormenta e tantos anos, tantas fezes e mijo diluído, na terra tanto berro e tanto esgano, tanta ruím idade poluída, onde pode acolher-se um pobre humano, onde verá lonjura a curta vista?" (p. 126)

Uma forte dimensão trágica atravessa o romance, indiciada também pela suspeita morte do latifundiário decadente e pelo enforcamento do velho criado, a qual, a par de um pessimismo envolvente, fazem com que a epígrafe de Eça de Queirós, um dos mestres do nosso romance oitocentista, que abre o romance - "pátria para sempre passada, memória quase perdida!" -ecoe ao longo dele. Pese

6. Os cacilheiros “São o que nos resta das descobertas e viagens, do apregoado império e seus naufrágios, dos sublimes sucessos, dos desastres em má hora anunciados por um velho de venerando aspecto, que ficara entre as gentes no cais, postos em nós os olhos, meneando três vezes a cabeça, descontente, a voz pesada um pouco alevantada, que nós no rio ouvimos claramente." (p., p. 14) 
embora o NÃO maiusculado de Marta no seu exílio dourado de Veneza, com que o romance se fecha, respondendo em acção ao desejo de ostracismo manifestado por J oão Carlos, a personagem central, ao dizer:

“apetece-me o ostracismo, a austeridade mais total, espécie de vida monástica" ( $p$. 140).

Estamos inquestionavelmente perante uma narrativa de destino em que o "estar" da pátria é sempre equacionado em função de seu "ser", da memória de uma Lusitânia passada que impõe uma visão pessimista do presente, mas que acaba por projectar-se em futuro pelo NÃO final.

Com A J angada de Pedra, é também o destino da pátria que está em causa, não a pátria isoladamente considerada, mas incorporada na I béria, entendida como um todo com uma especificidade própria. A pesar, ou exactamente por causa, da integração na Comunidade E uropéia (CE ) em curso, dá-se esse acontecimento fabuloso constituído pelo desprendimento da Península I bérica dos Pirinéus, a qual

"começou a mover-se, barca que se afasta do porto e aponta ao mar outra vez desconhecido." (p. 45)

Aqui a rememoriação da pátria faz-se evocando a vocação viajante e atlântica dos povos peninsulares. Todas as personagens do romance, portugueses e espanhóis, viajam pelos dois países ibéricos ou pelo mar, feitos Ulisses ou o Holandês Voador, aliás referidos no romance, numa deambulação à deriva, similar à da própria jangada de pedra em que se transformou a Península. São viagens sem rotas bem definidas, viagens de descoberta, todas elas precedidas por acontecimentos prodigiosos, viagens de busca, incluindo a da própria Península, que hesita no seu percurso, quase choca com os Açores, parece avançar para a América e finalmente acabará por fixar-se, algures no Atlântico, entre a África e a América do Sul, onde há cinco séculos atrás os descobridores ibéricos se fixaram, reencontrando assim o seu passado de ponte entre o velho e o novo mundo.

Subvertida a dimensão espacial, transformada em "ilha, ali quieta no meio do oceano" ( p. 297) , a Península simboliza claramente um espaço insular de utopia, o espaço matricial que o grupo viajante certamente busca de modo mais ou menos inconsciente. O tempo, também ele sofre uma suspensão:

“Não era inverno, outono não era, primavera nem pensar, verão também não podia ser. Era uma estação suspensa, sem data, como se estivéssemos no princípio do mundo e não tivessem sido ainda decididas as estações e os tempos para elas." (p. 302) 
Por seu turno que procurará a Península, para além de recusar o seu velho papel de periferia da E uropa e o seu novo papel de região continental de costas para o Atlântico? M etaforicamente, uma das personagens diz:

“esta outra ilha, a ibérica, que era península e deixou de o ser, vejo-a eu como se (...) tivesse decidido meter-se ao mar à procura dos homens imaginários" (p. 65) .

Os viajantes sonham sempre com uma ilha, no que ela simbolicamente carrea de refúgio e de espaço de perfeição primordial, onde seja possível começar tudo de novo; a Península feita ilha busca o seu passado, mas sobretudo procura reinventar um futuro próprio, longe da velha E uropa, reinventar “homens imaginários", num universo onde as coordenadas da normalidade são outras:

“Visto da península, o universo transformava-se pouco a pouco. ( ...) como se (...) estivesse a ser reorganizado duma ponta a outra, talvez por se achar que o primeiro não dera resultado." ( p. 301) - comenta o narrador.

Assim temos de novo a Península e com ela Portugal reocupando uma vocação esquecida, ou em vias de ser esquecida com o fim do império e a integração na CE, de inventor de novas Atlântidas, construtor de novos homens, num ritual de renascença mítica, indiciada pela gravidez simultânea de todas as mulheres férteis da Península, constatada no momento em que, enfim, a Península pára.

Mais uma vez neste romance que constitui, também ele, uma narrativa de destino, se rememora e futura, se questiona o "ser" da pátria, mas numa atitude esperançada, apostada numa renascença pátria, que integre simultâneamente o passado mítico.

De Angola, escolhemos duas narrativas: uma novela de Manuel Rui, Quem me dera ser onda, de 1984, que de algum modo confirma aquela tendência satírica da literatura angolana pós-independência de que falámos, e um recente romance de Pepetela, A Geração da Utopia, de 1992, que é uma aberta assunção do desencanto, num livro que continua muito preso à referência histórica.

Quem me dera ser onda gira em torno dos equívocos risíveis provocados pela iniciativa de criar um porco de engorda num andar de Luanda no sentido de escapar à escassez de alimentos que se vive na capital. O ponto de vista das crianças do prédio, que fazem do porco um animal de estimação, permite criticar ironicamente a corrupção da burocracia intermédia e desmistificar os propósitos pretensamente revolucionários da pequena-burguesia.

A Geração da Utopia, por seu turno, é um vasto friso do percurso vivencial e histórico da "geração de 50", claramente entendida como geração da utopia. 0 romance constitui-se em quatro partes, que cobrem as quatro décadas entre os 
anos 60 e 90, perseguindo a caminhada de um grupo de então jovens universitários angolanos, estudantes em Lisboa, desde a hora esperançada da eclosão dos movimentos de libertação, passando pelo exílio europeu, pela guerrilha anti-coIonial em Angola, até à chegada ao poder, ao seu exercício prevertido, ao desencanto.

A novela de Manuel Rui assenta numa estratégia carnavalesca que, recorrendo à ironia, põe perante o leitor o mundo às avessas, às avessas das normas dimanadas pelo imperativo nacional revolucionário, se bem que tais normas sejam a todo o instante reclamadas pelas personagens, pelo menos ao nível do exercício da linguagem. A verborreia revolucionária é parodiada, porque simplesmente incorporada acritica ou desadequadamente nas falas dos adultos ou porque é utilizada ingénua ou imitativamente pelas crianças. Termos como "fraccionista", “pequeno-burguês", “tribalista”, “corrupto", "reaccionário", “revolucionário" são constantemente utilizados pelas personagens.

Para que os vizinhos não ouvissem os grunhidos do porco, que está a ser cevado no apartamento, o pai sintoniza o rádio alto, o porco, obediente, rapidamente se habitua à música e passa até a reclamá-la, grunhindo, quando apagam o rádio: "-Estás-te a aburguesar" - reclama o chefe de família - "-Quem te viu e quem te vê. É a luta de classes!" (p. 24). A família improvisa uns auscultadores para colocar nos ouvidos do porco, de modo a simultânemaente agradar ao animal e calar a vizinhança que reclama contra a música demasiado alta; o porco reage bem, ficando como que anestesiado: "-Conquistas da revolução!" - rejubila o pai -"- Estás politizado! I sto é que a comissão de moradores devia ver.", a mãe protesta "- Mas assim nós nem sequer podemos ouvir o noticiário.", "-Porra, Liloca!” - irrita-se o pai - “M erdas da pequena-burguesia. Querem o céu e a terra. O capitalismo e o socialismo. Música e carne de porco". ( p. 26) Há que referir que o narrador, já páginas antes, anunciara que o animal em causa "era dos seres vivos que mais benefícios haviam tirado com a revolução." ( $p .22$ )

Como por acaso as crianças chamam ao porco "Carnaval", porque destinado a ser comido, após a engorda, por altura do Carnaval. Entretanto, nas suas artimanhas para poderem manter clandestinamente o porco no apartamento, ameaçam o fiscal, que viera em missão, com o facto de terem um primo na Segurança, o qual estaria a tomar banho, quando de facto o barulho proveniente do chuveiro era motivada pelo porco escondido. O fiscal, por subserviência para com a força discricionária, atemoriza-se, desiste e as crianças vitoriosas rebaptizam o porco - "Carnaval da Vitória". É evidentemente o carnaval da vitória angolana que o porco e toda a história rocambolesca a que dá origem metonimicamente representam.

“Carnaval da vitória" tem o seu destino traçado, chegado o Carnaval - "faca! é o fim de todos os burgueses!" (p. 27), ameaçava o pai. As crianças, afeiçoadas ao 
porco, usarão múltiplos estratagemas para desviar dos seus propósitos o "maníaco carnívoro" ( p. 50) em que o pai se tornara, a proclamar que "R evolução começa na barriga." ( p. 53) E m vão, "Carnaval da vitória” acaba em febras na brasa, deglutidas por todos os adultos do prédio, enfim pactuando com a situação. Tal como a revolução? - cabe perguntar.

M as a esperança persiste. Os meninos - o futuro - sem saberem, entretanto, que o porco já era carne, ainda "confiavam na força da esperança para salvar «carnaval da vitória»." (p. 69. Sublinhado meu) e uma delas exclama, sendo estas as derradeiras palavras do livro: “-Quem me dera ser onda!" (p. 69). Dias antes, um outro dos meninos, contemplando o mar, expressara o mesmo desejo. É que "se uma pessoa fosse [ onda] entrava com essa força do mar onde a gente queria. Onda ninguém amarra com corda." (p. 63) E is a utopia relançada em Quem me dera ser onda.

O romance de Pepetela, A Geração da Utopia, joga num outro tabuleiro: estamos perante um romance de tese, em que se procura evidenciar os percursos seguidos pela geração dos nacionalistas que se empenharam na luta pela independência e que, partindo de um ideal comum unitário acabam por assumir práticas políticas e vivenciais muito distintas, com implicações também distintas na relação com a pátria. Pretende-se orientar o leitor na compreensão das motivações de ordem socio-política e antroplógico-cultural do delta em que desaguou aquela geração heróica.

E mbora o narrador construa um romance polifónico, colocando-nos perante uma multiplicidade de vozes e de pontos de vista, dá maior destaque em cada uma das quatro partes a uma personagem diferente. Uma delas assume primeiro um protagonismo militante e depois um desencanto profético que conquista a adesão do leitor e trai o estatuto ideológico do narrador. Chama-se Aníbal, mas não por acaso o seu nome de guerra é "Sábio", nome que Ihe ficará para sempre colado à pele, até porque, ele próprio o diz: "ser sábio é ser incompreendido" (p. 221).

O Sábio, depois de ter desertado do exército português, apanhado na primeira mobilização de homens para a guerra colonial, depois de ter sido um quadro de elevada responsabilidade na guerrilha, reconhecidamente responsável por muitas vitórias, afasta-se do exército e da vida activa, logo em 1977, isto é, dois escassos anos após a independência, e torna-se uma espécie de ermita moderno, retirado numa falésia, contemplando o mar, gozando o sol, comendo o peixe que pesca, numa atitude de desencanto, alguma amargura e de descomprometimento crítico em relação ao processo político em curso que critica duramente, por desvirtuamento em relação às utopias juvenis. Ele mesmo admite que a sua "geração se devia chamar a geração da utopia", para concluir "A utopia morreu. E hoje 
cheira mal, como qualquer corpo em putrefacção. Dela só resta um discurso vazio." (p. 202)

O romance parece reivindicar, com o Sábio, "o direito à desilusão". Por vezes assoma a raiva por esse "passado de quimeras que trouxe este presente absurdo" ( p. 193) , mas o que persiste é o desencanto e a constatação de que a luta para a sua geração deixou de ser possível:

"Perdi poucas batalhas, mas sou um vencido. No fundo somos todos uns vencidos (...). Não temos futuro, nem representamos o futuro. J á somos o passado. A nossa geração consumiu-se. Fez o que tinha a fazer a dado momento, lutou, ganhou a independência. Depois consumiu-se. É preciso saber retirar se não temos mais nada para dar." (p. 214)

O futuro está vedado a esta geração, mesmo à parte dela que está no poder, responsável que foi por ter feito de Angola "um país de depredadores" (p. 303), onde reina o liberalismo economicista desenfreado, a corrupção, o desconcerto, a miséria, onde a barbárie se reinstala e o Estado caiu em descrédito. "Parece colono, pior que colono." ( p. 293), protesta um criado negro perante os maus tratos dos novos senhores.

O futuro não está aqui, fugiu das mãos da geração heróica que nos dois primeiros capítulos nos fora descrita nas suas convicções esperançadas, mas também nas suas contradições, designadamente naquelas que se foram definindo logo durante a luta anti-colonial e que depois vieram a eclodir na guerra civil pós-independência. Mais uma vez o futuro é dos jovens que reafirmam a esperança no final do romance, ao recusarem "o relento descrente do conformismo" ( $p$. 308) que perpassa na voz dos mais velhos. O passado não pode ser alibi para a passividade presente, reclama J udite. É certamente a sua voz que induz o narrador a não fechar o romance. A estranha palavra que o abre, "portanto", fecha-o, ou melhor, abre-o para um novo recomeço. O chamado "E pílogo" diz assim: "Como é óbvio, não pode existir epílogo nem ponto final para uma estória que começa por portanto." ( p. 316) Das cinzas renasce a utopia. E o Sábio pergunta-se: "Será o sul a minha última utopia?" ( p. 308)

Interrogar o "ser" da pátria parece ser, enfim, um traço comum às narrativas de destino pátrio, que dominam um filão significativo da ficção portuguesa actual e de algum do nosso ensaísmo, contribuindo ambos para continuar a inventar uma imagem de Portugal ou para a reinventar, em horas de procura de novos rumos, de outros destinos que todavia não deixam de integrar o passado mítico. São sempre narrativas de esperança e desesperança, de luz e sombra, feitas de certezas e de incertezas, de passado e de futuro, reclamando implícita ou explici- 
tamente um utópico "ser" da pátria, renegando o presente "estar" da pátria e projectando-se em futuro.

E as narrativas angolanas de que falámos, distanciar-se-ão muito, no equacionamento que fazem do destino da pátria, da orientação que vimos presente nas portuguesas? Sim e não.

Também elas são narrativas de destino, em que a pátria é objecto de ficção, também elas renegam o "estar" da pátria, embora recorrendo a soluções estéticas diferentes entre si e diferentes dos casos portugueses convocados. Mas aqui o "ser" da pátria é uma projecção, é ele próprio utopia, não é, nem pode ser objecto real e ficcional de rememoriação, como acontece no caso português. É utopia que conformiza o desencanto e o sarcasmo com que se renega o "estar" da pátria, é utopia projectando-se em futuro pelos descaminhos desconcertantes do presente. O "ser" da pátria é, para o ficcionista português, uma herança secular que ele não pode, não sabe e, provavelmente não quer alienar, coagindo-o indelevelmente a rememoriar. O "ser" da pátria, no caso angolano, é certamente uma utopia que as novas gerações, feitas ondas, poderão ainda vir a delinear: terá o nome de angolanidade ou não, será o que os angolanos quiserem, será, é tudo. “Será o sul a minha última utopia?" ( p. 308) - perguntava-se o Sábio. Lembram-se?

\section{Referências bibliográficas}

ALMEIDA FARIA. Lusitânia. Lisboa: Edições 70, 1980.

LOURE NÇO, Eduardo. Nós e a Europa ou as duas razões. 3 ed. Lisboa: I mprensa Nacional - Casa da Moeda, 1990.

. O labirinto da saudade. 3 ed. Lisboa: D. Quixote, 1988.

PEPETELA. A geração da utopia. 2 ed. Lisboa: D. Quixote, 1993.

QUADROS, Antonio. A idéia de Portugal na literatura portuguesa dos últimos cem anos. Lisboa: Fundação Lusíadas, 1989.

RUI, Manuel. Quem me dera ser onda. Lisboa: Cotovia, 1993.

SARAMAGO, J osé. A jangada de pedra. Lisboa: Editorial Caminho, 1986.

SOUSA SANTOS, B oaventura. 11/1992 (Onze teses por ocasião de mais uma descoberta de Portugal). In Via Latina. Coimbra: 58-64, maio 1991.

. Pela mão de Alice. O social e o político na pós-modernidade. Porto: Afrontamento, 1994.

. O Estado e a sociedade em Portugal (1974-1988). 2 ed. Porto: Afrontamento, 1992.

(Org.) Portugal - um retrato singular. Porto: Afrontamento, 1992.

VENÂNCIO, J osé Carlos. Literatura versus sociedade: Uma visão antropológica do destino angolano. Lisboa: Vega, 1992.

. Literatura e poder na África Iusófona. Lisboa: ICALP, 1992. 